\title{
The Development and Validation of a Thin Layer Chromatography Densitometry Method for the Analysis of Diclofenac Sodium Tablets
}

\author{
Eliangiringa Kaale ${ }^{1,3 *}$, Bugusu C Nyamweru' ${ }^{1}$, Vicky Manyanga ${ }^{1}$, Mhina Chambuso ${ }^{1}$ and Thomas Layloff ${ }^{2}$
}

${ }^{1}$ Pharm R\&D Laboratory, School of Pharmacy, Muhimbili University of Health and Allied Sciences, PO Box 650113, Dar es Salaam, Tanzania

${ }^{2}$ Supply Chain Management System, Arlington, VA, USA

${ }^{3}$ Institute of Pharmacy and Food Chemistry, Am Hubland 97074 Würzburg C7, Tanzania

\begin{abstract}
A Thin Layer Chromatography (TLC) method for the qualitative and quantitative analysis of diclofenac sodium tablets was developed and validated according to $\mathrm{ICH}$ and USP guidelines. The method was developed using a mobile phase prepared with environment-friendly solvents: toluene, acetone and glacial acetic acid (10:15:0.2 v/v/v), on pre-coated TLC silica gel $60 \mathrm{~F}_{254}$ glass plates with a saturation time of $25 \mathrm{~min}$ and a densitometer detection wavelength of $284 \mathrm{~nm}$ in the reflectance absorbance mode. The $R_{\mathrm{f}}$ of diclofenac sodium was at 0.60 and the method was repeatable, robust with good selectivity and specificity. Regression functions were established over the range of 250-600 ng/spot with $\mathrm{r}^{2}$ of 0.993 and 0.999 for the linear and polynomial regressions respectively. The accuracy at nominal concentration was found to be $100.2 \%$, and the results of the assay of three brands for diclofenac sodium tablets were found to meet the USP 95 to $105 \%$ assay limits thus demonstrating the usefulness of the method for the assay of these products.
\end{abstract}

The developed assay method for diclofenac sodium in tablets is simple, accurate, and inexpensive, with good precision and should be especially useful in resource constrained countries.

Keywords: Thin Layer Chromatography; Diclofenac sodium; Validation

\section{Introduction}

Diclofenac sodium is 2-(2-(2, 6-dichlorophenylamino) phenyl) acetic acid (Figure 1). It is a Nonsteroidal Anti-Inflammatory Drug (NSAID) with anti-inflammatory, antipyretic, and analgesic action as a result of the blockade of prostaglandin synthesis by inhibition of the cyclooxygenase (COX) enzyme. It also appears to exhibit bacteriostatic activity by inhibiting bacterial DNA synthesis [1-4].

Analysis of the Active Pharmaceutical Ingredient (API) as well as Finished Pharmaceutical Product (FPP) is of vital importance to help ensure that good quality products are manufactured and supplied to the patient end users.

Literature review revealed that various methods have been reported for analysis of diclofenac salts invarious formulations by High Performance Liquid Chromatography (HPLC) [4-7], High Performance TLC (HPTLC) [8-13], TLC [14], ultra violet-visible spectroscopy (UV-Vis) [15,16], spectrofluorometry [17] and colorimetry by derivatization of the diclofenac ring [18], and Gas Chromatography-Mass Spectrometry (GC-MS) for determination of<smiles>O=C(O)Cc1ccccc1Nc1c(Cl)cccc1Cl</smiles>

Figure 1: The Chemical structure of diclofenac. diclofenac in urine and plasma samples $[19,20]$. The developed TLC method has several advantages over other available methods such as ability to analyze several samples simultaneously in parallel, as well as using small quantities of solvents as a mobile phase which reduces time and cost of analysis. In addition, it minimizes exposure risks and significantly reduces disposal problems of toxic organic effluents, thereby reducing environmental pollution [21-23].

\section{Experimental}

\section{Solvents}

Analytical grade reagents obtained from various manufacturers were used for the method development and validation. These consisted of methanol and glacial acetic acid (Scharlau Chemie, Gato Perez, Spain), ethyl acetate, toluene, acetone and ammonia solution (Fisher Scientific, Leicestershire, UK). Purified water was prepared by reverse osmosis in-house with a RO- Purification System Millipore ${ }^{\circledR}$ (France). Excipients used for simulation to determine specificity included microcrystalline cellulose (FMC BioPolymer, Philadelphia), sodium carboxymethyl cellulose and polyvinylpyrrolidone cross-linked (Associate Co. Ltd, Shenzhen, China), as well as magnesium stearate (Shandong Liaocheng Ehua Medicine Co. Ltd, China).

*Corresponding author: Eliangiringa Kaale, Pharm R\&D Laboratory, School o Pharmacy, Muhimbili University of Health and Allied Sciences, PO Box 650113 Dar es Salaam, Tanzania, E-mail: Eliangiringa.Kaale@uni-wuerzburg.de

Received December 06, 2012; Accepted January 23, 2013; Published January 25,2013

Citation: Kaale E, Nyamweru BC, Manyanga V, Chambuso M, Layloff T (2013) The Development and Validation of a Thin Layer Chromatography Densitometry Method for the Analysis of Diclofenac Sodium Tablets. Pharmaceut Anal Acta 4 202. doi:10.4172/2153-2435.1000202

Copyright: (C) 2013 Kaale E, et al. This is an open-access article distributed unde the terms of the Creative Commons Attribution License, which permits unrestricted use, distribution, and reproduction in any medium, provided the original author and source are credited. 
Citation: Kaale E, Nyamweru BC, Manyanga V, Chambuso M, Layloff T (2013) The Development and Validation of a Thin Layer Chromatography Densitometry Method for the Analysis of Diclofenac Sodium Tablets. Pharmaceut Anal Acta 4: 202. doi:10.4172/2153-2435.1000202

Page 2 of 4

\section{Reference standards and sample tablets}

Diclofenac sodium reference material was obtained from SigmaAldrich, Belgium. Diclofenac sodium tablets $(50 \mathrm{mg})$ were obtained from Fourrts Company, India; Remedica, Cyprus; and Zenufa Laboratories, Tanzania.

\section{Equipment}

Instrumentation used during method development consisted of a densitometer with a TLC Scanner 3 operated with Wincats (version 1.4.3) planar chromatograph software that was used as data manager and integrator, a Linomat 5 automatic sample applicator with a Hamilton syringe of $100 \mu \mathrm{L}$ capacity for sample application and a rectangular flat bottomed developing tank (CAMAG, Muntenz, Switzerland). The TLC plates used for chromatographic sample separations $(5 \times 10 \mathrm{~cm}$ and $20 \times 10 \mathrm{~cm}$ )were pre-coated with silica gel $60 \mathrm{~F}_{254}$ (Merck, Darmstadt, Germany) [24].

\section{Method development}

Preparation of sample stock and working solutions: Samples were prepared by accurately weighing powdered tablets equivalent to $20 \mathrm{mg}$ of diclofenac sodium into a $10 \mathrm{~mL}$ volumetric flask that was dissolved in methanol to obtain stock concentration of $2 \mathrm{mg} /$ $\mathrm{mL}$. Further dilution was made using methanol to obtain a working concentration of $0.2 \mathrm{mg} / \mathrm{mL}$ by diluting $1 \mathrm{~mL}$ of the stock solution into a $10 \mathrm{~mL}$ volumetric flask.

Chromatography: Since the TLC plates were activated, they were freshly removed from their packing only when in use and it was not necessary to pre-wash them. Before spotting the plate was labeled and solvent front marked at $70 \mathrm{~mm}$ from the bottom. $5 \mu \mathrm{L}$ were applied at $8 \mathrm{~mm}$ from the bottom as $8 \mathrm{~mm}$ band using a Linomat 5 applicator. After application the plate was dried with hot air before developing. Filter paper was placed to aid saturation at one side of the developing tank and the mobile phase poured by wetting it and the lid closed for 25 minutes to allow the tank to saturate before the plate was developed. After the plate was developed and dried it was scanned using a TLC Scanner 3 in the reflectance absorbance mode with Wincats (version 1.4.3) planar chromatograph software for data acquisition and some calculations.

Selection of suitable mobile phase: From literature survey the following solvents were identified as potential candidates for the method development: toluene, methanol, ethyl acetate, acetone, glacial acetic acid, formic acid and chloroform. Chloroform was omitted due to its carcinogenic potential. Toluene was substituted for chloroform and glacial acetic acid was used in place of formic acid $[2,3,8-13]$. The solvents were combined in various ratios taking into consideration their polarities and the lipophilicity of the analyte to optimize the mobile phase for separation of diclofenac sodium.

Method validation: After method optimization, a validation protocol was prepared based on the ICH Q2R1 guidelines and USP guidance and the validation was performed $[2,24]$.

\section{Results and Discussion}

\section{Selection of suitable mobile phase}

Various combinations of solvents were used during method development, such as toluene:methanol $(17: 3 \mathrm{v} / \mathrm{v})$; toluene: methanol $(20: 10 \mathrm{v} / \mathrm{v})$ (Figure 2); toluene; methanol $(15: 15 \quad \mathrm{v} / \mathrm{v}) ; \quad$ toluene:methanol:ammonia solution $\quad(17: 3: 0.2$ $\mathrm{v} / \mathrm{v} / \mathrm{v}) ; \quad$ toluene:methanol:ammonia solution (20:5:0.1 $\mathrm{v} / \mathrm{v} / \mathrm{v})$; toluene:methanol:glacial acetic acid $(20: 5: 1 \mathrm{v} / \mathrm{v} / \mathrm{v})$; toluene:ethyl acetate $(17: 4 \mathrm{v} / \mathrm{v}) ;$ toluene:ethylacetate $(20: 10 \mathrm{v} / \mathrm{v}) ;$ toluene:ethylacetate:ammonia solution (20:10:0.1 v/v/v); toluene:ethylacetate:glacial acetic acid $(20: 10: 0.2 \mathrm{v} / \mathrm{v} / \mathrm{v})$ and toluene:acetone $(10: 20 \mathrm{v} / \mathrm{v})$. The mobile phase containing toluene:acetone $(10: 20 \mathrm{v} / \mathrm{v})$ was selected for optimization. The mobile phase toluene:acetone:glacial acetic acid was varied as [(10:20:0.05), (10:20:0.1), (10:18:0.2), (10:18:0.5), (10:15:0.2) v/v/v]. Diclofenac sodium with a working concentration at $100 \%$ at $0.2 \mathrm{mg} /$ $\mathrm{mL}$ showed good peak resolution with mobile phase composition of toluene: acetone:glacial acetic acid (10:15:0.2 v/v/v). The optimum saturation time was determined to be 25 minutes and the development time of 6 minutes had a migration distance of $70 \mathrm{~mm}$ at room temperature $\left(23\right.$ to $\left.28^{\circ} \mathrm{C}\right)$ with a relative humidity between 36 and $54 \%$. The optimum wave length was determined to be $284 \mathrm{~nm}$ after scanning the developed plate from $200 \mathrm{~nm}$ to $800 \mathrm{~nm}$ using the deuterium and tungsten lamps.

\section{Method validation}

The assay method was validated for specificity, linearity, precision, accuracy and robustness [24].

Method robustness: The robustness of the assay method was tested by varying the acetone: glacial acetic acid mobile phase solvent composition ratio $\pm 5 \%$ and the saturation times that were established during method development against critical parameter: $\mathrm{R}_{\mathrm{f}}$. The changes in the $R_{f}$ values were found to be $0.60 \pm 0.02$ which showed that the method was robust.

Specificity and selectivity: Both the solvent and simulated excipients were used during each chromatographic plate run. The densitograms that were obtained during method development showed that the method was specific for the assay and selective for the API and that there were no interferences from the excipients or solvents showing that the method was acceptable for assay of diclofenac sodium (Figures 3-6).

Linearity: Evaluation of linearity of the diclofenac sodium assay was demonstrated by preparing five standard concentrations ranging from $50 \%$ to $120 \%$ (500 to 1200 ) ng/spot using serial dilutions from a stock solution. Spots were applied at the plate for each concentration starting with lowest concentration to avoid carryover effect. The procedure

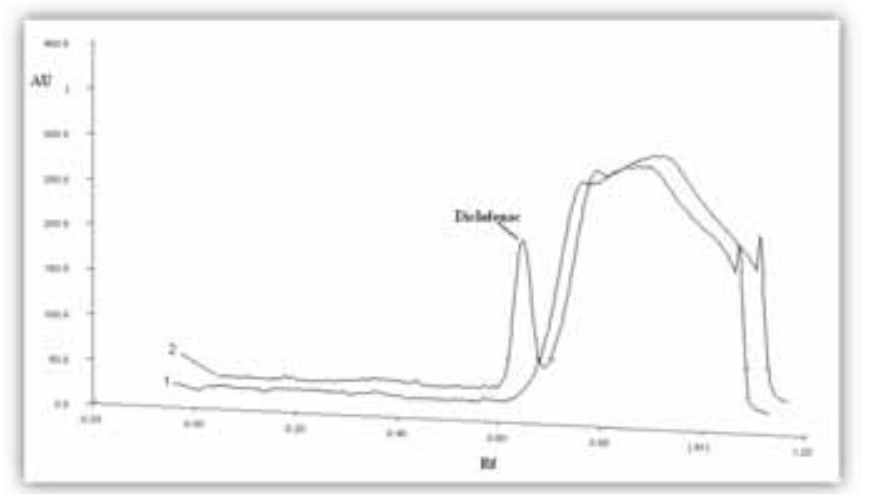

Figure 2: Typical densitograms of a solution containing diclofenac sodium using a mobile phase containing toluene:methanol $(20: 10 \mathrm{v} / \mathrm{v})$, saturation time of 20 min using $5 \mathrm{~cm} \times 10 \mathrm{~cm}$ TLC silica gel $60 \mathrm{~F}_{254}$ plate and application volume was $5 \mu \mathrm{L}$ at a detection wave length of $284 \mathrm{~nm}$. Where track 1: Blank/methanol and track 2 : diclofenac sodium $(0.1 \mathrm{mg} / \mathrm{mL}), R_{\mathrm{f}} 0.55$ 
Citation: Kaale E, Nyamweru BC, Manyanga V, Chambuso M, Layloff T (2013) The Development and Validation of a Thin Layer Chromatography Densitometry Method for the Analysis of Diclofenac Sodium Tablets. Pharmaceut Anal Acta 4: 202. doi:10.4172/2153-2435.1000202

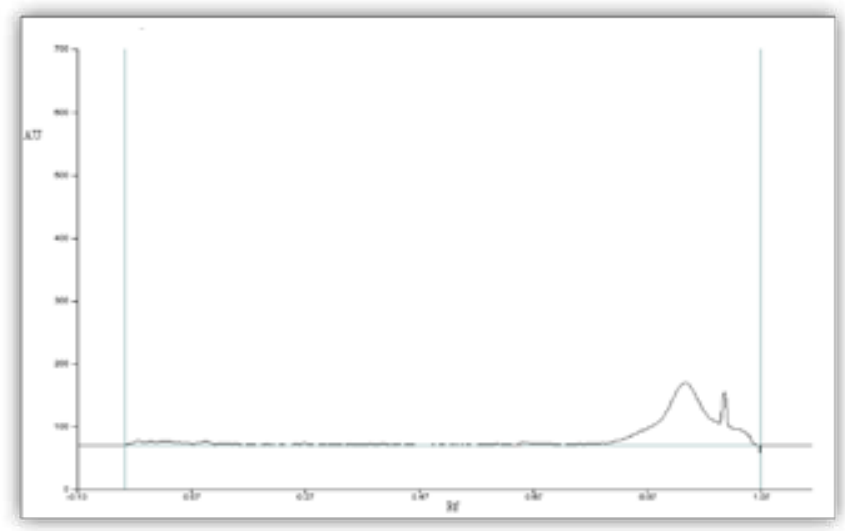

Figure 3: Typical densitogram of methanol used as a blank by using a mobile phase containing toluene: acetone: glacial acetic acid $(10: 15: 0.2 \mathrm{v} / \mathrm{v} / \mathrm{v})$ saturation time of $20 \mathrm{~min}$ using $5 \mathrm{~cm} \times 10 \mathrm{~cm}$ TLC silica gel $60 \mathrm{~F}_{254}$ plate and application volume was $5 \mu \mathrm{L}$ at a detection wave length of $284 \mathrm{~nm}$.

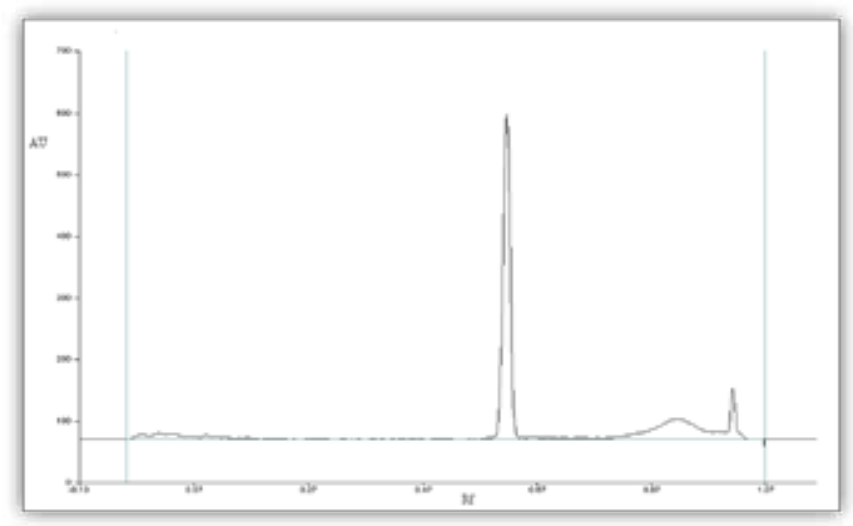

Figure 4: Typical densitogram of a solution containing diclofenac sodium using a mobile phase containing toluene: acetone: glacial acetic acid $(10: 15: 0.2 \mathrm{v} / \mathrm{v} / \mathrm{v})$, saturation time of 20 min using $5 \mathrm{~cm} \times 10 \mathrm{~cm}$ TLC silica gel 60 $\mathrm{F}_{254}$ plate and application volume was $5 \mu \mathrm{L}$ at a detection wave length of 284 $\mathrm{nm}$, diclofenac sodium $(0.2 \mathrm{mg} / \mathrm{mL})$ had $\mathrm{R}_{\mathrm{f}} 0.60$.

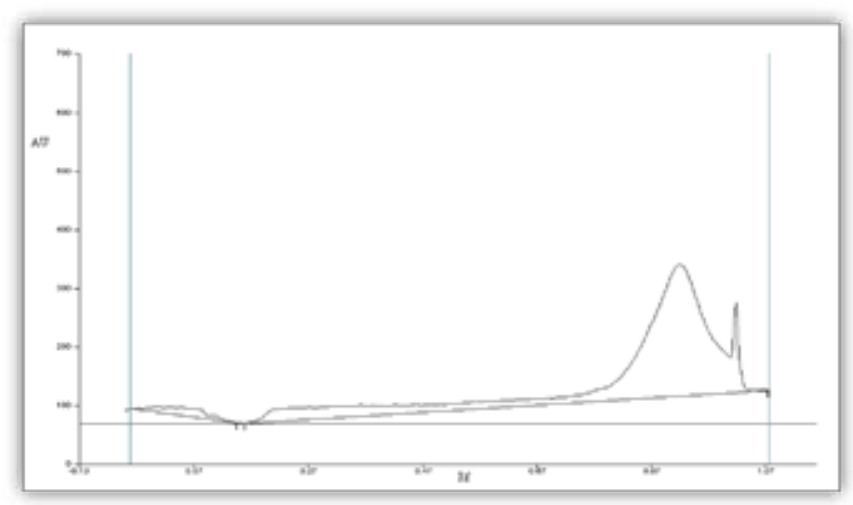

Figure 5: Typical densitogram of simulated Placebo mixture of excipients used as a blank by using a mobile phase containing toluene: acetone: glacial acetic acid $(10: 15: 0.2 \mathrm{v} / \mathrm{v} / \mathrm{v})$, saturation time of 20 min using $5 \mathrm{~cm} \times 10 \mathrm{~cm}$ TLC silica gel $60 \mathrm{~F}_{254}$ plate and application volume was $5 \mu \mathrm{L}$ at a detection wave length of $284 \mathrm{~nm}$.

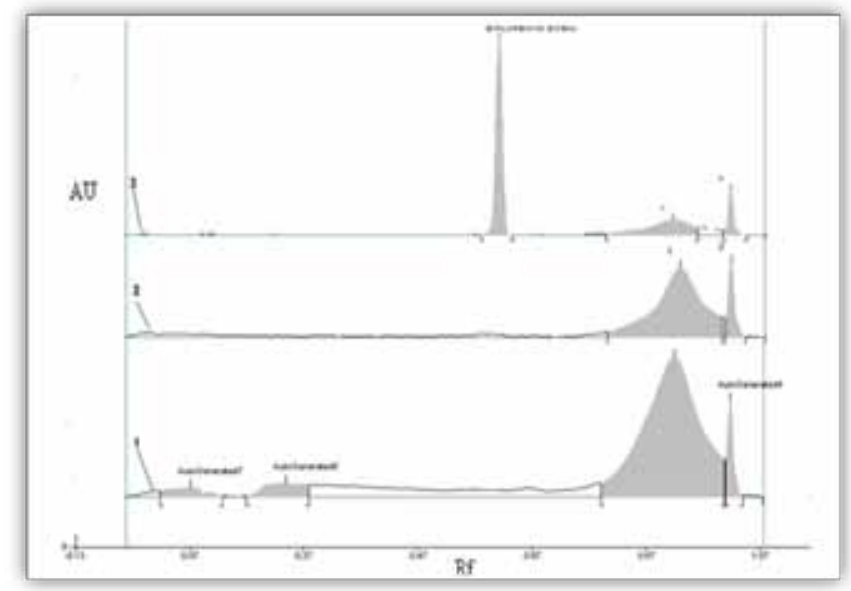

Figure 6: Typical densitograms obtained during method specificity test (1) Placebo mixture of excipients in methanol (2) methanol and (3) diclofenac sodium. The chromatographic conditions consisted of mobile phase toluene: acetone: glacial acetic acid $(10: 15: 0.2 \mathrm{v} / \mathrm{v} / \mathrm{v})$ at a saturation time of $25 \mathrm{~min}$, on a $20 \mathrm{~cm} \times 10 \mathrm{~cm}$ TLC silica gel $60 \mathrm{~F}_{254}$ plate with application volume of $5 \mu \mathrm{L}$, and detection at $284 \mathrm{~nm}$. Diclofenac sodium $(0.2 \mathrm{mg} / \mathrm{mL})$ had a $R_{\mathrm{f}}$ of 0.60 .

was repeated for three days. The results were analyzed via peak area of the developed spot. Both the linear $\left(r^{2}=0.993\right)$ and polynomial $\left(r^{2}=0.999\right)$ functions were evaluated and both cases had $r^{2}>0.98$ though polynomial regression which was superior to that shown in table 1 and was selected for use during accuracy testing.

Precision: Repeatability and intermediate precision were done for the assay method using sample tablets in which six replicate sample solutions were prepared independently, corresponding to $100 \%$ level of assay concentration. Intermediate precision was done by two analysts performing the procedure on different days. The calculated percentage relative deviations ( $\% \mathrm{rsd}$ ) by using peak areas were found to be 1.1 and 3.8 for repeatability and intermediate precision as shown in tables 2 and 3.

Accuracy: Accuracy was evaluated by determination of percentage of standard diclofenac sodium spotted as controls by using a calibration curve at 80,100 and $120 \%$ of the assay concentrations. The controls were weighed in triplicate for each concentration and were spotted on a separate plate in triplicate. Assay of sample tablet was done where percentage assay at $100 \%$ was determined using the calibration curve. The accuracy was within limits at concentration of 100 and $120 \%$ according to USP [2] with value of 100 and $99 \%$ while at a concentration of $80 \%$ the accuracy was $103 \%$ (Table 4 ) of the various brands of diclofenac sodium tablets were tested using the method and all were found to be within the USP [2] limits of 95\% to 105\% (Table 5).

\section{Conclusion}

A facile and robust HPTLC assay technique for diclofenac sodium tablets was developed and validated according to ICH and USP guidelines $[2,24,25]$. Compared to some previously reported methods, $[4-7,19,20]$ the method is simple, accurate, and inexpensive for the routine analysis of diclofenac sodium tablets using environmentally friendly solvents.

The method is repeatable and robust with good selectivity and specificity. Moreover, the assay results obtained showed that the sample tablets met the USP acceptance criteria of 95 to $105 \%$ of the label claim 
Citation: Kaale E, Nyamweru BC, Manyanga V, Chambuso M, Layloff T (2013) The Development and Validation of a Thin Layer Chromatography Densitometry Method for the Analysis of Diclofenac Sodium Tablets. Pharmaceut Anal Acta 4: 202. doi:10.4172/2153-2435.1000202

\begin{tabular}{|c|c|c|}
\hline Parameter & Polynomial regression & Linear regression \\
\hline Concentration range(ng/spot) & $500-1200$ & $500-1200$ \\
\hline $\mathrm{x}^{2}$-coefficient & -0.0001 & - \\
\hline $\mathrm{x}$-coefficient & 4.509 & 2.890 \\
\hline $\mathrm{y}$-intercept & 1,819 & 2,464 \\
\hline $\mathrm{r}^{2}$ & 0.999 & 0.993 \\
\hline
\end{tabular}

Table1: Linear and polynomial regression equations obtained from the TLC densitometric method for diclofenac sodium.

\begin{tabular}{|l|l|}
\hline Parameter & Sample repeatability \\
\hline \% Concentration & 100 \\
\hline Mean & 5146 \\
\hline Sd & 56.6 \\
\hline \% rsd & 1.1 \\
\hline $\mathrm{n}$ & 6 \\
\hline
\end{tabular}

$\mathrm{n}=$ number of replicate samples

Table 2: Repeatability of diclofenac sodium assay.

\begin{tabular}{|c|c|c|c|}
\hline Parameter & Analyst-1 & Analyst -2 & Average \\
\hline \% Concentration & 100.00 & 100.00 & 100.00 \\
\hline Mean & $4,806.02$ & $5,081.47$ & $4,943.74$ \\
\hline Sd & 76.14 & 156.63 & 185.68 \\
\hline$\%$ rsd & 1.58 & 3.08 & 3.80 \\
\hline $\mathrm{n}$ & 6 & 6 & 12 \\
\hline
\end{tabular}

$\mathrm{n}=$ number of replicate samples

Table 3: Intermediate precision for diclofenac sodium using two analysts.

\begin{tabular}{|c|c|c|c|}
\hline Concentration levels & $\mathbf{8 0} \%$ & $\mathbf{1 0 0} \%$ & $\mathbf{1 2 0} \%$ \\
\hline \% Recovery & 103.37 & 100.19 & 98.94 \\
\hline Sd & 7.07 & 5.42 & 13.61 \\
\hline$\%$ rsd & 1.60 & 1.10 & 2.60 \\
\hline
\end{tabular}

Table 4: Accuracy values for diclofenac sodium.

\begin{tabular}{|l|l|l|}
\hline Product & Manufacturer & $\begin{array}{l}\text { Percentage per label } \\
\text { claim }\end{array}$ \\
\hline Ziclofen-50 Batch-1 & Zenufa Laboratories Ltd Tanzania & 103.71 \\
\hline Ziclofen-50 Batch-2 & Zenufa Laboratories Ltd Tanzania & 103.14 \\
\hline Remethan 50 & Remedica Cyprus & 101.23 \\
\hline Diclofen 50 & Fourrts India & 100.61 \\
\hline
\end{tabular}

Table 5: Assay of diclofenac sodium tablet using the developed method.

which shows that the method is suitable for quantifying diclofenac sodium in tablets and thus is suitable for routine drug screening and analysis especially in resource constrained countries.

\section{Acknowledgement}

We thank the Tanzania office of the Supply Chain Management System (SCMS) for supporting the purchase of reference standards and plates. This purchase was made possible through funding provided by the US Agency for International Development, under the terms of contract number GPO-I-00-05-00032-00.

Also we acknowledge the technical contribution from members and staf of Pharmaceutical Research and Development Laboratory (Pharm R\&D Lab) Muhimbili University of Health and Allied Sciences Mr. Maro Mhando, Mr. Prosper Tibalinda, Ms. Ruth Ng'wananogu, Ms. Bertha Francis and Mr. Edson Ruta.

\section{References}

1. Wikipedia: Diclofenac sodium, accessed on 28 July, 2012.

2. The United States Pharmacopoeia, United States (2010): 683.

3. British Pharmacopoeia (2005) Assays \&Tests. The Stationery Office UK: 2408.

4. Sundaram PS, Phanindra SS, Thiyagarajan SN, Aanandhi MV (2008) Validated RP-HPLC Method for the Simultaneous Determination of Diclofenac Potassium and Tizanidine Hydrochloride in Tablet Dosage Form. Trade Sci Inc 7: 6.
5. Umarkar AR, Rewatkar NS (2011) Validated Spectrophotometric Determination of Pazufloxacin in Formulation. J Pharm Res 4:1307.

6. Kasperek R (2008) Determination of Diclofenac Sodium and Papaverine Hydrochloride in Tablets by HPLC Method. Acta Poloniae Pharm Drug Res 65: 403-408.

7. Gonzalez L, Yuln G, Volonte MG (1999) Determination of cyanocobalamin betamethasone, and diclofenac sodium in pharmaceutical formulations, by high performance liquid chromatography. J Pharm Biomed Anal 20: 487-492.

8. Rathnam MV, Singh MV (2010) Simultaneous RP HPLC Determination of Camylofin Dihydrochloride and Diclofenac Potassium in Pharmaceutical Preparations. Pharm Anal Acta 1:108.

9. Wisanu T, Boonsom L, Saisunee L (2009) Flow injection analysis of tota curcuminoids in turmeric and total antioxidant capacity using 2,2B 0-diphenyl1-picrylhydrazyl assay. Food Chem 112: 494-499.

10. Nageswara Rao K, Ganapaty S, Lakshmana Rao A (2013) RP-HPLC Determination Of Rifaximin In Bulk Drug And Pharmaceutical Formulations. Int J Pharm 3: 7-13

11. Lala LG, D'mello PM, Naik SR (2002) HPTLC determination of diclofenac sodium from serum. J Pharm Biomed Anal 29: 539-544.

12. Khatal LD, Kamble AY, Mahadik MV, Dhaneshwar SR (2010) Validated HPTLC method for simultaneous quantitation of paracetamol, diclofenac potassium, and famotidine in tablet formulation. J AOAC Int 93: 765-770.

13. Dhaneshwar SR, Bhusari VK (2011) Validated HPTLC Method for Simultaneous Estimation of Diclofenac Sodium and Misoprostol in Bulk Drug and Formulation. Asian J Pharm Biol Res 1: 15-21.

14. Ali M, Sudhanshu S (2009) Separation of Co-Existing Paracetamol and Diclofenac Sodium on Silica Gel H Layers using Surfactant Mediated Mobile Phases:Identification of Diclofenac Sodium from Human Urine. FARMACIA 57 201-211.

15. Sena MM, Chaudhry ZF, Collins CH, Poppi RJ (2004) Direct determination of diclofenac in pharmaceutical formulations containing $B$ vitamins by using UV spectrophotometry and partial least squares regression. J Pharm Biomed Ana 36: 743-749.

16. Revathi G, Rama RN, Venkata SP (2012) Int J Drug Dev \& Res 4: 316.

17. Damiani PC, Bearzotti M, Cabezón MA, Olivieri AC (1999) Spectrofluorometric determination of diclofenac in tablets and ointments. J Pharm Biomed Anal 20 587-590.

18. Olakunle SI, Olajire AA, Bolaji AO, Ajibola AO (2006) J Pharm Sci 19: 134

19. Segura J, Mestres M, Aubets J, de la Torre R, Ugena B, et al. (1988) Detection and quantification of non-steroidal anti-inflammatory agents by gas chromatography/mass spectrometry: diclofenac. Biomed Environ Mass Spectrom 16: 361-365.

20. Sioufi A, Pommier F, Godbillon J (1991) Determination of diclofenac in plasma and urine by capillary gas chromatography-mass spectrometry with possible simultaneous determination of deuterium-labelled diclofenac. J Chromatogr 571: $87-100$.

21. Kaale E, Risha P, Reich E, Layloff T (2010) An interlaboratory investigation on the use of high-performance thin layer chromatography to perform assays of lamivudine-zidovudine, metronidazole, nevirapine, and quinine composite samples. J AOAC Int 93: 1836-1843.

22. Kaale E, Risha P, Layloff T (2011) TLC analysis for pharmaceutical analysis in a resource limited countries. International symposium for TLC, Base Switzerland.

23. WHO (1994) International program on chemical safety, WHO Geneva.

24. WHO (2000) Pharmaceuticals Newsletter 2000, No. 03.

25. ICH Topic Q2 (R1) Validation of Analytical Procedures: Text and methodology 